\title{
Obesity in patients with craniopharyngioma (CP) seems to be caused by eating disorders rather than changes in mood or activity
}

\author{
Roemmler J. ${ }^{1}$, Geigenberger V. ${ }^{1}$, Dimopoulou C. ${ }^{1,2}$, Sievers C. ${ }^{2}$, Stalla G. ${ }^{2}$, Schopohl J1 \\ Medizinische Klinik und Poliklinik IV, Klinikum der Universität München, Germany', Max-Planck-Institute of Psychiatry, Department of \\ Endocrinology, Munich, Germany²
}

\section{INTRODUCTION}

It is still unclear whether obesity in patients with craniopharyngioma (CP) is caused by disorders in food regulation or by changes in mood or activity due to depression or sleepiness leading to a decrease in energy consumption. We compared CP to patients with non-functioning pituitary adenoma (NFPA) by using standardized questionnaires to clarify this question.

\section{METHODS}

We compared $31 \mathrm{CP}(\mathrm{m}=14, \mathrm{f}=17$, median age: 53 years [26-77]) to 26 NFPA ( $m=19, \mathrm{f}=7$, median age: 65 years [44-80], BMI: CP $31 \mathrm{~kg} / \mathrm{m}^{2}$ [20-66] vs. $28 \mathrm{~kg} / \mathrm{m}^{2}$ [22-40], $\mathrm{p}=0.017$ ). All patients with NFPA had macroadenomas. Patients were asked to complete eleven standardized German questionnaires. Two questionnaires evaluated eating disorders (FEV, Eating-Disorder-Examination-Questionnaire), one depression (BDI = Beck-Depression-Inventory), one anxiety (STAI = State-Trait Anxiety Inventory), three health-related quality of life (SF-36, EuroQoL, Qol-AGHDA), one sleepiness (Epworth Sleepiness Scale), two personality (EPQ-RK = Eysenck Personality Questionnaire-Revised, $\mathrm{TPQ}=$ Tridimensional Personality Questionnaire) and one body image (FKB-20).

\section{RESULTS}

Figure 1
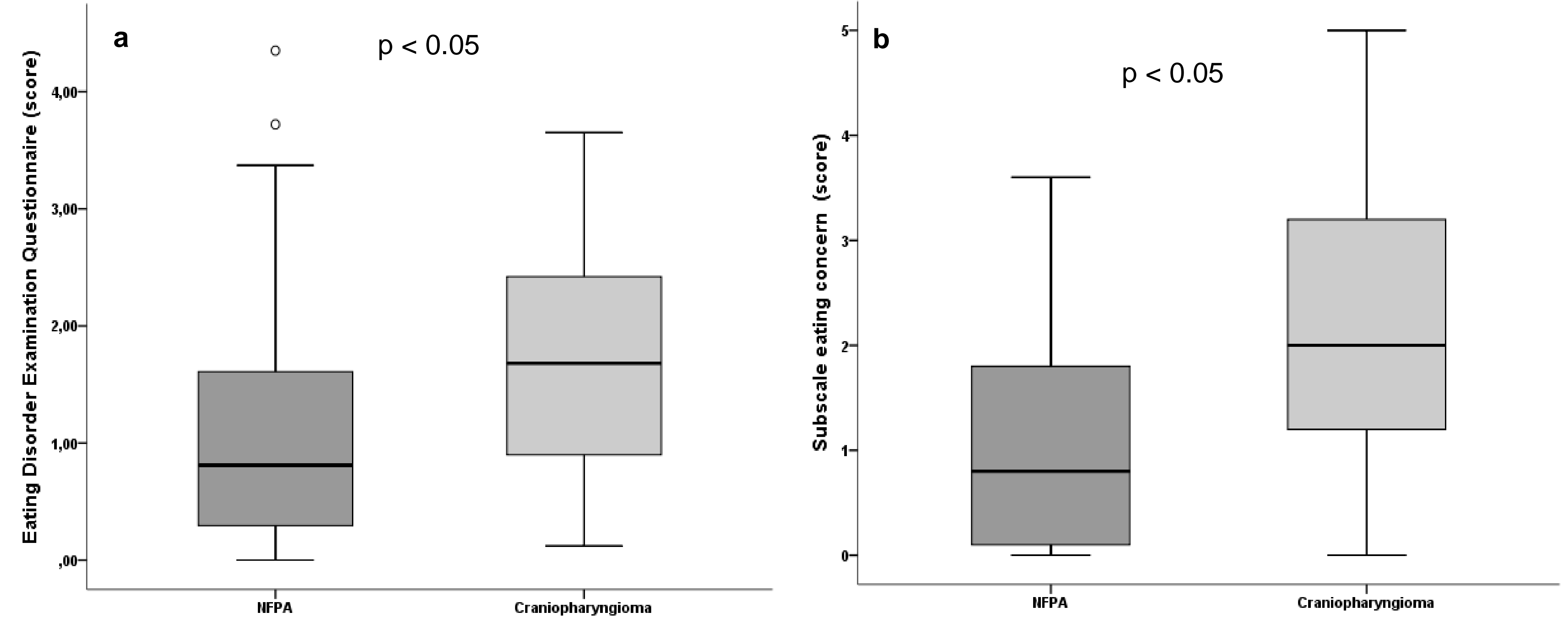

Figure 1: Patients with $\mathrm{CP}$ scored significantly higher in the Eating-Disorder-ExaminationQuestionnaire (CP 1.7 scores (0.1-3.7), NFPA 0.8 scores (0-4.4) p=0.039, Fig 2a, control population $\left.1.44 \pm 1.2^{*}\right)$. This difference is due to significantly higher scores in the subscale eating concern of patients with CP (CP 2 scores (0-5), NFPA 0.8 scores $(0-6), p=0.047$, Fig $2 \mathrm{~b}$, control population $0.76 \pm 1.08^{*}$ ). Values are given in median and range.

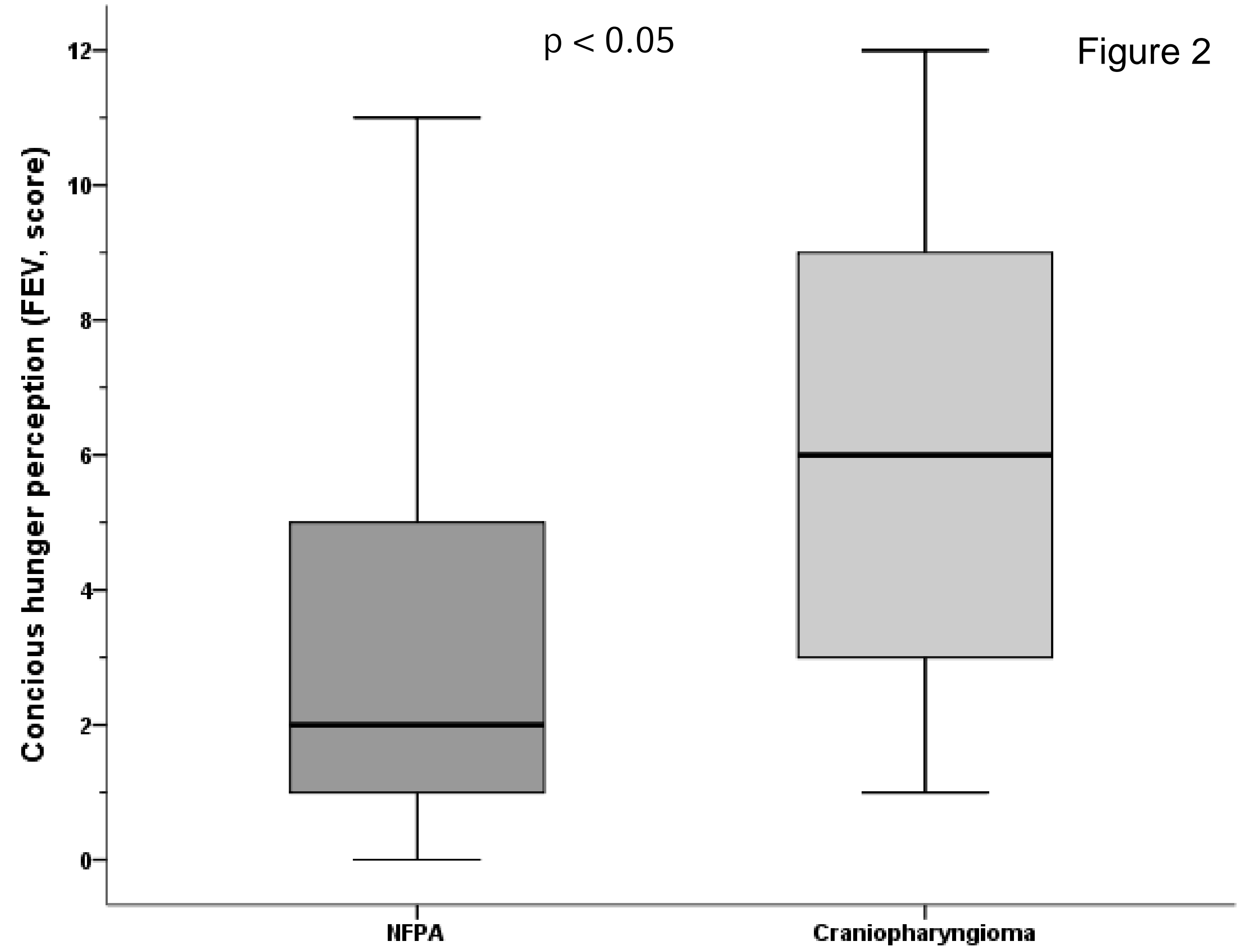

Figure 2: Patients with $\mathrm{CP}$ scored significantly higher in concious hunger perception compared to patients with NFPA (FEV, CP 6 scores (1-12), NFPA 2 scores $(0-11), p=0.016)$. Values are given in median and range.

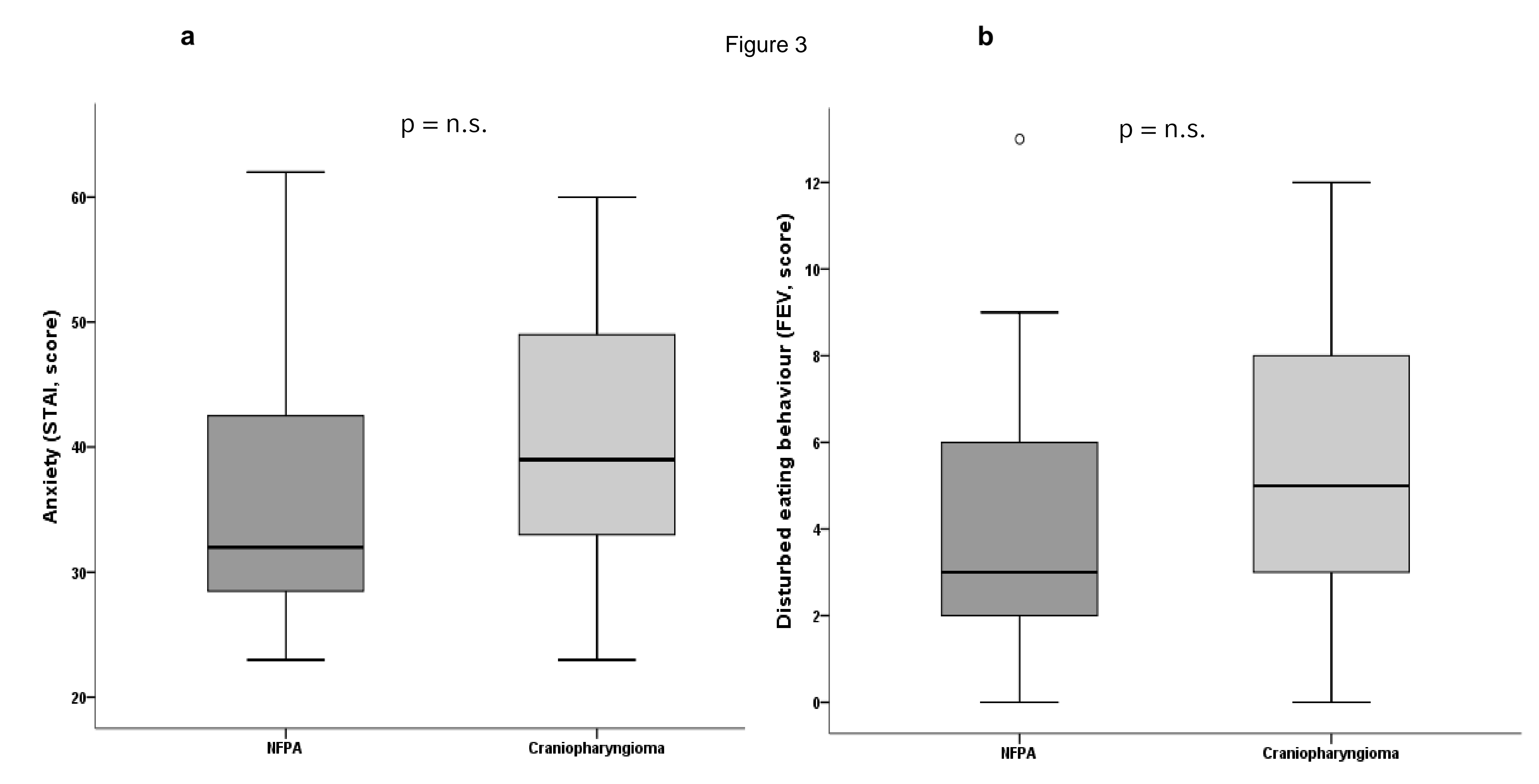

Figure 3: Patients with CP had higher scores in anxiety (STAI, CP 39 scores (23-60), NFPA 32 scores (23-62), $p=0.052$, Fig 4a) and disturbed eating behaviour (FEV, CP 5 scores (0-12), NFPA 3 scores $(0-13), p=0.064$, Fig $4 b)$, but without reaching statistical significance. Values are given in boxplots showing median and range. No differences could be seen in depression, personality, quality of life or sleepiness (data not shown).

\section{SUMMARY \& DISCUSSION}

Patients with craniopharyngioma score higher in questionnaires of eating disorders than patients with nonfunctioning pituitary adenoma but not in questionnaires concerning mood or impulse. Therefore, obesity in CP appears to be a consequence of eating disorders. 